\title{
Ti-Pd-Ni high temperature shape memory thin films formed with carousel type magnetron sputtering apparatus
}

\author{
T. Sawaguchi, M. Sato and A. Ishida \\ $5^{\text {th }}$ Research Group, $2^{\text {nd }}$ Subgroup, National Research Institute for Metals (NRIM), \\ 1-2-1 Sengen, Tsukuba, Ibaraki 305-0047, Japan
}

\begin{abstract}
High temperature shape memory thin films of Ti-Pd-Ni were formed with a carousel type magnetron sputtering apparatus. Four kinds of films with different compositions (a Ti-rich, a near stoichiometric, and two (Pd, Ni)-rich films) were prepared by independently applying D.C. powers to each pure metal target. The near stoichiometric sample with a composition of $\mathrm{Ti}_{49.5} \mathrm{Pd}_{28.5} \mathrm{Ni}_{22.0}$ was found to consist mainly of a Ti ( $\left.\mathrm{Pd}, \mathrm{Ni}\right)$ phase, and showed a shape memory effect at about $500 \mathrm{~K}$ with a recoverable transformation strain of $2.9 \%$ and a plastic strain of $0.3 \%$ at $160 \mathrm{MPa}$. The Ti-rich film with a composition of $\mathrm{Ti}_{51.2} \mathrm{Pd}_{27.0} \mathrm{Ni}_{21.8}$ was found to contain a $\mathrm{TiPd}_{2}$ type second phase, and showed a shape memory effect at about $490 \mathrm{~K}$ with a smaller recoverable transformation strain of $1.5 \%$ and a smaller plastic strain of $0.05 \%$ than those of the near stoichiometric film. One of the (Pd, Ni)-rich films with a composition of $\mathrm{Ti}_{47.9} \mathrm{Pd}_{29.8} \mathrm{Ni}_{22.3}$ was found to possess both $\mathrm{B} 2$ and $\mathrm{B} 19$ phases at ambient temperature, and showed a shape memory effect at $360 \mathrm{~K}$ with a recoverable transformation strain of $2.5 \%$ almost as large as the near stoichiometric film, and showed a plastic strain of $0.05 \%$ as small as that of the Ti-rich film.
\end{abstract}

\section{I.INTRODUCTION}

Shape memory thin films are expected to be used as microactuators such as micropumps and microvalves because of their advantages such as large deformation and strong recovery force. Particularly, sputter-deposited thin films of $\mathrm{Ti}-\mathrm{Ni}$ are promising candidates[1-3], since they exhibit perfect shape memory effects comparable to those in bulk specimens of $\mathrm{Ti}-\mathrm{Ni}[4]$ and have sufficient ductility[5]; besides, these films can be easily integrated into micromachining process. In addition, the shape memory characteristics are strongly affected by heat-treatment, alloy composition and sputtering conditions. It has been reported that Ti-rich Ti-Ni thin films annealed under proper conditions show good ductility unlike bulk specimens[6].

Recently, shape memory thin films with higher transformation temperatures have been demanded for higher actuation responses and for higher temperature applications. Since the improvement of film characteristics by precipitation hardening reduces transformation temperatures of films, the development of materials with intrinsically high transformation temperatures is important. From this viewpoint, Ti-Pd-Ni alloys are desirable, because the transformation temperatures in these alloys can be successively varied from ambient temperature up to above $700 \mathrm{~K}$ by replacing $\mathrm{Ni}$ with $\mathrm{Pd}[7,8]$. Miyazaki et al. have reported that a $\mathrm{Ti}-26.4 \mathrm{Ni}-21.8 \mathrm{Pd}(\mathrm{at} \%)$ thin film shows a high temperature shape memory effect at about $385 \mathrm{~K}[9,10]$. Quandt et al. have prepared $\mathrm{TiNi}, \mathrm{Ti}\left(\mathrm{Ni}_{0.8} \mathrm{Pd}_{0.2}\right), \mathrm{Ti}\left(\mathrm{Ni}_{0.4} \mathrm{Pd}_{0.6}\right)$, and $\mathrm{TiPd}$ thin films and measured transformation temperatures by DSC measurement, succeeding in changing transformation temperatures from ambient temperature to around $700 \mathrm{~K}[11]$.

In this study, the dependence of the shape memory characteristics of Ti-Pd-Ni thin films on film composition, especially $\mathrm{Ti} /(\mathrm{Pd}, \mathrm{Ni})$ ratio, was investigated. In such multicomponent systems, however, there are few satisfactory methods of controlling the film composition. We succeeded in overcoming this problem with a carousel type magnetron sputtering apparatus. The film composition can be controlled by independently applying the electrical power to each pure metal target. Four kinds of Ti-Pd-Ni shape memory thin films with different compositions were formed. It was investigated whether these films show high temperature shape memory effects or not. Furthermore, the dependence of the shape memory characteristics on the film composition is discussed. 


\section{EXPERIMENTAL}

Fig. 1 shows the carousel type magnetron sputtering apparatus used in this study. Six glass substrates were placed on the sides of a cylindrical substrate holder. The substrate holder was rotated at $60 \mathrm{rpm}$, and $\mathrm{Ti}, \mathrm{Pd}$ and $\mathrm{Ni}$ targets were independently sputtered with different D.C. powers. D.C power at the Ti target was fixed at $800 \mathrm{~W}$, and those consumed at the $\mathrm{Pd}$ and $\mathrm{Ni}$ targets were varied from 70 to $89 \mathrm{~W}$, and from 133 to $183 \mathrm{~W}$, respectively, in order to control the film composition. The other conditions were as follows: substrate temperature, 473K; Ar gas pressure, $0.3 \mathrm{~Pa}$ (base pressure, $2.1 \times 10^{-5} \mathrm{~Pa}$ ); deposition time: 2 hours.

After sputtering, films were removed from glass substrates. The film composition was determined by inductively coupled plasma atomic emission spectroscopy (ICP-AES). Table 1 shows film compositions and film thicknesses under four combinations of D.C. powers consumed at each metal target. A Ti-rich $\left(\mathrm{Ti}_{51.2} \mathrm{Pd}_{27.0} \mathrm{Ni}_{21.8}\right)$, a near stoichiometric $\left(\mathrm{Ti}_{49.5} \mathrm{Pd}_{28.5} \mathrm{Ni}_{22.0}\right)$, and two ( $\mathrm{Pd}, \mathrm{Ni}$ )-rich $\left(\mathrm{Ti}_{47.9} \mathrm{Pd}_{29.8} \mathrm{Ni}_{22.3}, \mathrm{Ti}_{45.6} \mathrm{Pd}_{26.3} \mathrm{Ni}_{28.1}\right)$ films were obtained. Hereinafter, the symbols of "Ti51", "Ti50", "Ti48", and "Ti46" are used, respectively.

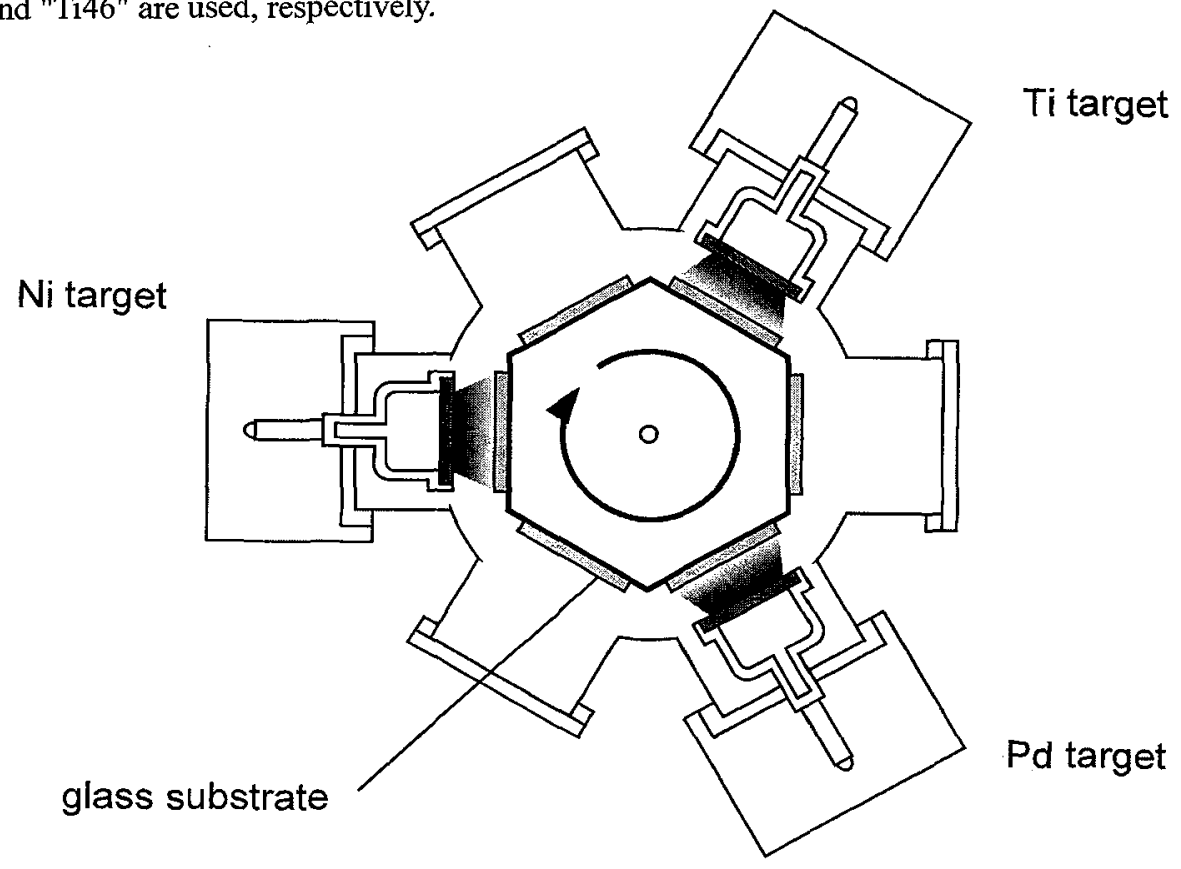

Fig. 1. Carousel type magnetron sputtering apperatus

Table 1. D.C. powers, film compositions and film thicknesses

\begin{tabular}{llll}
\hline Sample name & D.C. powers $(W)$ & Film composition & Film thichness $(\mu$ m) \\
\hline Ti51 & Ti: 800 ; Pd: 70; Ni: 133 & Ti51.2Pd27.0Ni21.8 & 7.0 \\
Ti50 & Ti: 800; Pd: 79; Ni: 148 & Ti49.5Pd28.5Ni22.0 & 7.8 \\
Ti48 & Ti: $800 ; \mathrm{Pd}: 89 ; \mathrm{Ni}: 157$ & Ti47.9Pd29.8Ni22.3 & 8.2 \\
Ti46 & Ti: $800 ; \mathrm{Pd}: 70 ; \mathrm{Ni}: 183$ & Ti45.6Pd26.3Ni28.1 & 8.1 \\
\hline
\end{tabular}


In order to produce crystallization of $\mathrm{Ti}(\mathrm{Pd}, \mathrm{Ni})$, they were annealed at $973 \mathrm{~K}$ for 1 hour in a vacuum, and quenched with $\mathrm{Ar}$ gas. The phase formed in the films were identified by $\mathrm{X}$-ray diffraction. The shape memory behavior of these films was measured with a thermomechanical tester. The size of the sample was $1 \times 5 \mathrm{~mm}^{2}$ (gauge portion) and the thickness was from 7.0 to $8.2 \mu \mathrm{m}$. The samples was loaded at a high temperature, and then cooled at the rate of $-10 \mathrm{~K} / \mathrm{min}$ and heated back at the rate of $10 \mathrm{~K} / \mathrm{min}$. A series of strain-temperature measurements under various stresses was carried out with one sample by varying the stress from 20 to $160 \mathrm{MPa}$ in steps of $20 \mathrm{MPa}$.

\section{RESULTS AND DISCUSSION}

\subsection{X-ray diffraction}

Figure 2 shows X-ray diffraction patterns of as-sputtered thin films, indicating that they are almost amorphous. After annealing at $973 \mathrm{~K}$ for 1 hour, the films were crystallized as shown in Fig. 3. The near stoichiometric sample (Ti50) was found to consist mainly of a B19 type (Orthorhombic) martensite phase. Sivokha et al. have reported that the martensitic transformations in $\mathrm{Ti}_{50} \mathrm{Pd}_{\mathrm{x}} \mathrm{Ni}_{50-\mathrm{x}}(0 \leqq \mathrm{x} \leqq 50)$ system occur via $\mathrm{B} 2$ (cubic) $\rightarrow \mathrm{R}$ (Rhombohedral) $\rightarrow \mathrm{B} 19^{\prime}$ (Monoclinic) for lower $\mathrm{Pd}$ content $(\mathrm{x}=1.0,2.8$ ), and via $\mathrm{B} 2 \rightarrow$ $\mathrm{B} 19 \rightarrow \mathrm{B} 19^{\prime}$ for immediate $\mathrm{Pd}$ content $(\mathrm{x}=7.4,11.4,13.5)$. Furthermore, for higher Pd content $(\mathrm{x} \geqq 15.7)$, only $\mathrm{B} 2 \rightarrow \mathrm{B} 19$ has been observed, since the transformation temperature from $\mathrm{B} 19$ to $\mathrm{B} 19^{\prime}$ is pretty low (less than $77 \mathrm{~K}$ at least)[12]. The martensitic transformation from $\mathrm{B} 2$ to $\mathrm{B} 19$ is considered to have finished above ambient temperature in Ti50. There appear three other small peaks. However, they have not been identified yet.

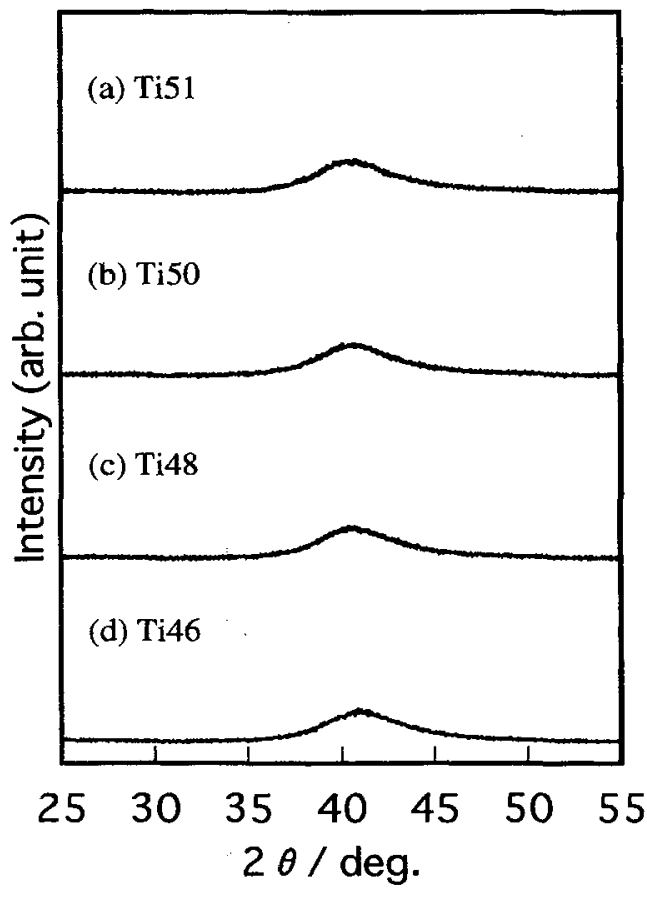

Fig 2. X-ray diffraction paterns of as-sputtered Ti-Pd-Ni thin films.

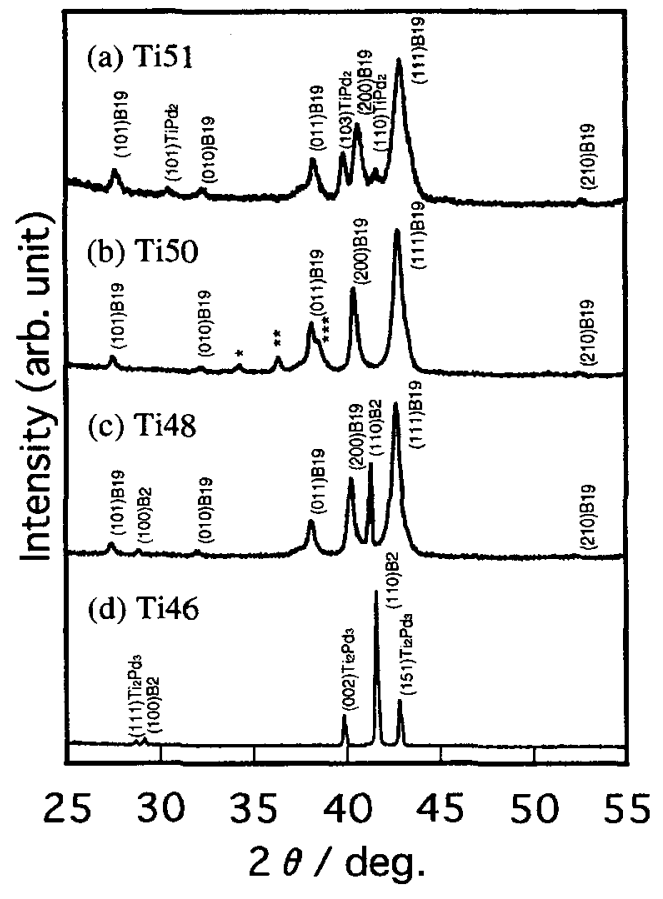

Fig 3. X-ray diffraction paterns of Ti-Pd-Ni thin films annealed at $973 \mathrm{~K}$ for 1 hous. $(*, * *, * * *:$ not identified) 
The Ti-rich sample (Ti51) shows peaks from a TiPd ${ }_{2}$ type second phase besides $\mathrm{B} 19$. The solid solution curve of $\mathrm{Ti}(\mathrm{Pd}, \mathrm{Ni})$ is considered to lie between $\mathrm{Ti}$ contents of 49.5 and $51.2 \mathrm{at} \%$ at $973 \mathrm{~K}$. One of (Pd, Ni)-rich sample (Ti48) shows both of peaks from B19 and those from B2. This means that the martensitic transformation has started above ambient temperature, but has not finished in this sample at ambient temperature. The other ( $\mathrm{Pd}, \mathrm{Ni}$ )-rich sample (Ti46) shows peaks from B2, indicating that the martensitic transformation start temperature is below ambient temperature. Ti46 also shows the existence of a $\mathrm{Ti}_{2} \mathrm{Pd}_{3}$ type second phase.

As a result, we succeeded in preparation of $\mathrm{Ti}(\mathrm{Pd}, \mathrm{Ni})$ thin films with different $\mathrm{Ti} /(\mathrm{Pd}, \mathrm{Ni})$ ratios with the carousel type magnetron sputtering apparatus.

\subsection{Shape Memory behavior}

Figure 4 shows strain-temperature curves of Ti-Pd-Ni thin films annealed at 973K for 1 hour. They were measured under three different stresses, 40,80 , and $160 \mathrm{MPa}$. Shape memory effects corresponding to the martensitic transformations from B2 to B19 were observed in Ti51, Ti50, and Ti48. Ti46 shows no shape memory effect in the temperature range from $150 \mathrm{~K}$ to $523 \mathrm{~K}$.

The martensitic transformation start and finish temperatures, and reverse martensitic transformation start and finish temperatures (hereinafter denoted as $\mathrm{O}_{\mathrm{s}}, \mathrm{O}_{\mathrm{f}}, \mathrm{AO}_{\mathrm{s}}$ and $\mathrm{AO}_{\mathrm{f}}$, respectively) were determined from strain-temperature curves, as shown in Fig. 4. The temperature hysteresis is defined as a difference between $\mathrm{O}_{\mathrm{S}}$ and $\mathrm{AO}_{\mathrm{f}}$. The recoverable transformation strain, $\varepsilon_{\mathrm{A}}$ and the plastic strain, $\varepsilon_{\mathrm{p}}$ were also obtained from Fig. 4

Ti50 shows shape memory effects in the highest temperature range among the samples. The mostly perfect shape memory effect is shown at $40 \mathrm{MPa} . \mathrm{O}_{s}, \mathrm{O}_{\mathrm{f}}, \mathrm{AO}_{\mathrm{s}}$ and $\mathrm{AO}_{\mathrm{f}}$ points are $483 \mathrm{~K}$, $477 \mathrm{~K}, 499 \mathrm{~K}$, and $508 \mathrm{~K}$ at $40 \mathrm{MPa}$, respectively. They slightly increase with increasing stress. The temperature hysteresis is about $20 \mathrm{~K}$, in accord with the values reported in the previous work[10]. This value is smaller than those of $\mathrm{Ti}-\mathrm{Ni}$ thin films of about $30 \mathrm{~K}$. This is an advantage for the practical uses as microactuators, since smaller temperature hysteresis produces higher response. This has been usually explained by the smaller lattice deformation at $\mathrm{B} 2 \rightarrow \mathrm{B} 19$ transformation than that at $\mathrm{B} 2 \rightarrow \mathrm{B} 19^{\prime}$ transformation. The recoverable transformation strain is $0.7 \%$ at $40 \mathrm{MPa}$. They increase to $2.9 \%$ with increasing

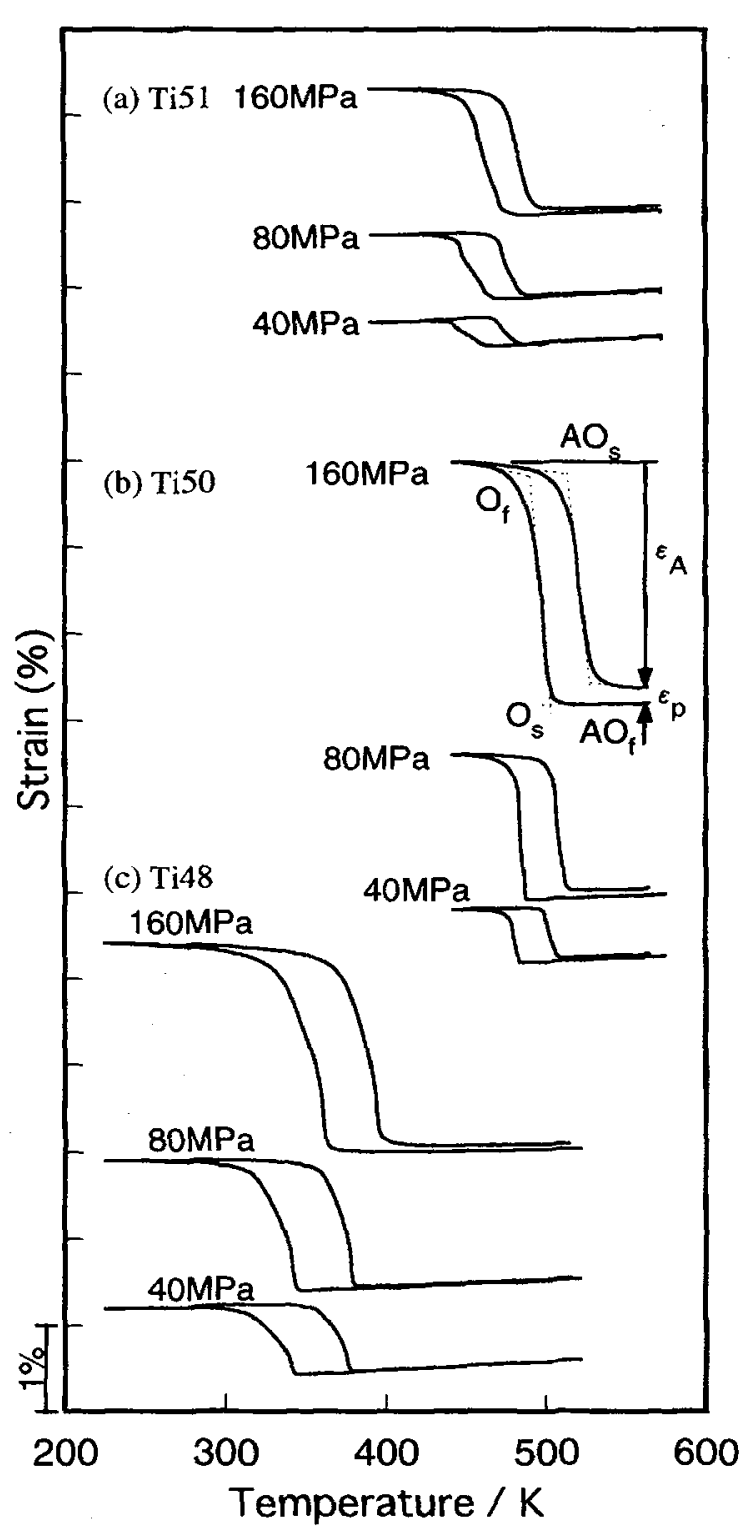

Fig. 4. Strain-temperature curves under various stresses of Ti-Pd-Ni thin films annealed at $973 \mathrm{~K}$ for 1 hour. 
stress to $160 \mathrm{MPa}$. However, the plastic strain also increases to $0.3 \%$ with increasing loading stress to $160 \mathrm{MPa}$. Consequently, Ti50 does not show a perfect shape memory effect any longer.

The transformation temperatures of Ti51 are somewhat lower than those of Ti50. $\mathrm{O}_{\mathrm{s}}, \mathrm{O}_{\mathrm{f}}, \mathrm{AO}_{\mathrm{s}}$ and $\mathrm{AO}_{\mathrm{f}}$ points at $40 \mathrm{MPa}$ are $462 \mathrm{~K}, 441 \mathrm{~K}, 468 \mathrm{~K}$, and $483 \mathrm{~K}$, respectively. This sample exhibits smaller elongation than Ti50. The recoverable transformation strain is $0.4 \%$ at $40 \mathrm{MPa}$, and is limited within $1.5 \%$ even at $160 \mathrm{MPa}$. The plastic strain is also small, and is limited within $0.05 \%$ even at $160 \mathrm{MPa}$. Consequently, this sample shows a perfect shape memory up to $80 \mathrm{MPa}$. The hardness of this sample is considered to be owing to precipitation hardening caused by a $\mathrm{TiPd}_{2}$ second phase.

$\mathrm{O}_{\mathrm{s}}, \mathrm{O}_{\mathrm{f}}, \mathrm{AO}_{\mathrm{s}}$ and $\mathrm{AO}_{\mathrm{f}}$ points of $\mathrm{Ti} 48$ at $40 \mathrm{MPa}$ are $343 \mathrm{~K}, 310 \mathrm{~K}, 355 \mathrm{~K}$, and $376 \mathrm{~K}$, respectively. It is noteworthy that this sample shows not only the plastic strains almost as small as that of Ti51, but also the deformation as large as Ti50. The recoverable transformation strain and the plastic strain at $160 \mathrm{MPa}$ are $2.5 \%$ and $0.05 \%$, respectively. This sample exhibits a perfect shape memory effect with a recoverable transformation strain of $1.6 \%$ at the $\mathrm{O}_{\mathrm{s}}$ point of $345 \mathrm{~K}$ at $80 \mathrm{MPa}$. This is the optimum condition in the present article. However, the temperature hysteresis of this sample is about $30 \mathrm{~K}$, unexpectedly, which is larger than those of Ti50 and Ti51. Some kinds of microstructures might concern the shape memory characteristics of this $(\mathrm{Pd}, \mathrm{Ni})$-rich sample, though there appears no new phase in the $\mathrm{X}$-ray diffraction as shown in Fig. 3.

Transformation temperatures of samples obtained from the strain-temperature curves can be explained by the results of X-ray diffraction satisfactorily. Transformation temperatures are also affected by $\mathrm{Pd}$ content substituting $\mathrm{Ni}$ as well as $\mathrm{Ti} /(\mathrm{Pd}, \mathrm{Ni})$ ratio. Shimizu et al. have measured the transformation temperatures by DSC measurements in plasma melted $\mathrm{Ti}_{50-\mathrm{x}} \mathrm{Pd}_{30} \mathrm{Ni}_{20+\mathrm{x}}(0 \leqq \mathrm{x} \leqq 50)$ alloys, and concluded that they increase from about $300 \mathrm{~K}$ to about $500 \mathrm{~K}$ with increasing $\mathrm{Ti}$ content from 48.5 to 50.2 at $\%$, and stay almost same (slightly decrease) with increasing $\mathrm{Ti}$ content from 50.2 to 50.6at\%[13]. Transformation temperatures of Ti51, Ti50 and Ti48 are nearly coincident with these values. In addition, those of Ti51 show further decreases probably because of precipitation hardening by a $\mathrm{TiPd}_{2}$ type second phase. Transformation temperatures of Ti46 are far less than those of the other samples, not only because Ti content is smaller, but also because $\mathrm{Pd}$ content is smaller than those of the others. Furthermore, a $\mathrm{Ti}_{2} \mathrm{Pd}_{3}$ type second phase may cause further decrease owing to precipitation hardening.

As a result, high temperature shape memory characteristics of Ti-Pd-Ni thin films were found to be controlled by varying film composition, especially $\mathrm{Ti} /(\mathrm{Pd}, \mathrm{Ni})$ ratio. In order to clarify the effect of the microstructure on the shape memory characteristics, the detailed microscopic observations are under way.

\section{CONCLUSION}

A Ti-rich $\left(\mathrm{Ti}_{51.2} \mathrm{Pd}_{27.0} \mathrm{Ni}_{21.8}\right)$, a near stoichiometric $\left(\mathrm{Ti}_{49.5} \mathrm{Pd}_{28.5} \mathrm{Ni}_{22.0}\right)$, and two (Pd, $\left.\mathrm{Ni}\right)$-rich $\left(\mathrm{Ti}_{47.9} \mathrm{Pd}_{29.8} \mathrm{Ni}_{22.3}, \mathrm{Ti}_{45.6} \mathrm{Pd}_{26.3} \mathrm{Ni}_{28.1}\right)$ thin films were formed with a carousel type magnetron sputtering apparatus, and the shape memory characteristics of the films annealed at $973 \mathrm{~K}$ for $1 \mathrm{~h}$ were investigated. The results obtained in the present article are as follows.

(1) Ti-Pd-Ni shape memory thin films can be formed with a carousel type magnetron sputtering apparatus. We succeeded in controlling the film composition.

(2) The near stoichiometric sample was found to consist mainly of a $\mathrm{Ti}(\mathrm{Pd}, \mathrm{Ni})$ phase, and showed a shape memory effect at about $500 \mathrm{~K}$ with a recoverable transformation strain of $2.9 \%$ and a plastic strain of $0.3 \%$ at $160 \mathrm{MPa}$.

(3) The Ti-rich sample was found to contain a $\mathrm{TiPd}_{2}$ type second phase, and showed a shape memory effect at about $490 \mathrm{~K}$ with a smaller recoverable transformation strain of $1.5 \%$ and a smaller plastic strain of about $0.05 \%$ than those of Ti50 at $160 \mathrm{MPa}$.

(4) One of $(\mathrm{Pd}, \mathrm{Ni})$-rich sample with the composition of $\mathrm{Ti}_{47.9} \mathrm{Pd}_{29.8} \mathrm{Ni}_{22.3}$ was found to possess both $\mathrm{B} 2$ and B19 phases at ambient temperature, and showed a shape memory effect at $360 \mathrm{~K}$ with a recoverable transformation strain of $2.5 \%$ almost as large as Ti50 and a plastic strain of about $0.05 \%$ 
as small as that of Ti50 at $160 \mathrm{MPa}$.

(5) The other ( $\mathrm{Pd}, \mathrm{Ni})$ - rich sample with the composition of $\mathrm{Ti}_{45.6} \mathrm{Pd}_{26.3} \mathrm{Ni}_{28.1}$ was found to contain a $\mathrm{Ti}_{2} \mathrm{Pd}_{3}$ type second phase, and showed no shape memory effect above $150 \mathrm{~K}$.

\section{References}

1. A.D. Jhonson, J. Microeng., 1, 34 (1991).

2. L. Hou, T.J. Pence, D.S. Grummon, Mater, Res. Soc. Symp. Proc., 360, 369 (1990).

3. S. Miyazaki, A. Ishida, A. Takei, Proc. ICOMAT-92, Monterey, Carmel, (1993) p. 893.

4. A. Ishida, S. Miyazaki, ASME J. Eng. Mater. Technol., 121, 2 (1998).

5. A. Ishida, A. Takei, S. Miyazaki, Thin Solid Films, 228, 210 (1993).

6. A. Ishida, M. Sato, S, Miyazaki, Philos. Mag. A 80, 967 (2000)

7. N.M. Matveeva, Y.K. Kovneristyi, A.S. Savinov, V.P. Sivikha, V.N. Khachin, Proc. ICOMAT-82, Leuven, Belgium, (1982) p. 249.

8. K. Enami, Y. Kitano, K. Horii, Mater. Res. Soc. Proc., 9, 117 (1989).

9. S. Miyazaki, T. Hashinaga, K. Yumikura, H. Horikawa, T. Ueki, A. Ishida, Smart Mater. SPIE, 2441, 156 (1995).

10. S. Miyazaki, K. Nomura, A. Ishida, J. Phys. IV FRANCE, 7, C5-275 (1997).

11. E. Quandt, C. Halene, H. Holleck, K. Feit, M. Kohl, P. Schloßmacher, A. Skokan, K.D. Skrobanek, Sensors and Actuators A, 53, 434 (1996).

12. V.P. Sivokha, A.S. Savinov, V.P. Voronin, V.N. Khachin, Phys. Met. Metall, 56, 112 (1983).

13. S. Shimizu, Y. Xu, E. Okunishi, S. Tanaka, K. Otsuka, K. Mitose, Mater. Lett., 34, 23 (1998). 